\title{
Modeling The Use of History of Mathematical Thought in Mathematics Instruction
}

\author{
Chinedu Victor Obasi \\ Department of Mathematics, Alvan Ikoku Federal College of Education Owerri, Imo State, Nigeria \\ *Corresponding author: obasi1212@gmail.com
}

\section{ARTICLE HISTORY}

Received : 12 February 2020

Revised : 26 February 2020

Accepted : 8 March 2020

\section{KEYWORDS}

Mathematics;

History of Mathematical

Thought;

\begin{abstract}
Mathematics is a human creation, which has been developing for more than four thousand years. It emerged as a response to different social and economic needs of civilizations. Historical development of mathematics stresses that mathematics as a science has always been connected to economic and social context and development of society. There is little or no research that promotes using historical content in mathematics lessons in the Nigeria context. In this paper, we model the use of history of mathematical thought (HMT) in mathematics instruction and solved the formulated model equation using integrating factor. The rate at which HMT is used by teachers in mathematics instruction is assumed to be proportional to the number of teachers that do not use HMT. The analysis suggests that with time, only a fraction of teachers can use HMT in teaching mathematics due to the fact that they will not remember to use it, and additional recruitment of teachers will result in only marginal improvement in the usage of HMT.
\end{abstract}

This is an open access article under the CC-BY-SA license.

\section{INTRODUCTION}

The language of mathematics has changed the way we think about the world. Most of our science and technology would have been literally unthinkable without mathematics. Clearly, mathematics is an important core subject in the secondary schools curriculum. The subject is indispensable to national goals and objectives hence it is made compulsory for every student in both primary and secondary schools. This great emphasis is placed upon the learning of mathematics because of its utility to the individuals as well as to the nation at large (Obasi, 2014). For better or worse, you cannot comprehend the influence of mathematics until you have some understanding of history of mathematical thought (HMT).

History of mathematical thought (HMT) is primarily an investigation into the origin of discoveries in mathematics and, to a lesser extent, an investigation into the mathematical methods and notation of the past. History of mathematical thought can be very useful in mathematics teaching because it fosters students' sense that mathematics is a changing and evolving domain, one in which ideas grow and develop over time and to which many cultural groups have contributed. Drawing on the history of mathematical thought can help teachers to portray this idea: exploring alternative enumeration systems or investigating non-Euclidean geometries, for example. Fractions evolved out of the Egyptians' attempts to divide quantities- four things shared among ten people. This fact could provide the explicit basis for a teacher's approach to introducing fractions. Educational goals that can be served by the use of historical topics in the mathematics classroom include the following (Obasi, Uwakwe \& Ihemaguba, 2018):
- To show by concrete examples that the foundations for school mathematics were created, in large part, in Africa and Asia, and to correct the false idea that mathematics is an exclusively European product.

- To humanize the teaching of mathematics by showing the development of mathematics as a human response to human needs.

- To help all students learn mathematics by showing that mathematics developed by going from the concrete to the abstract, much as students do in mastering mathematics.

- To encourage students to experiment by trying methods and manipulative from other cultures.

To provide role models for students and to encourage mutual respect among students of all ethnic backgrounds.

In the views of Dejić and Mihajlović (2014), one of the reasons we use history of mathematics in the teaching and learning of the subject is that we believe that if mathematical theories are seen only through their final formulation, without historical interpretations, students can gain a wrong impression about mathematics: they seem to then see it as an artificial creation, which serves mental imagination, but has no connection to practical work or real-life contexts. According to them, this can be overcome when students, through historical facts, understand that mathematics from its foundation up to now has played one 
of the most significant roles in all areas of human life. Students can gain an insight into mathematical concepts in a deeper and more interesting way and from many examples from the past can understand that mathematics is not an isolated discipline (Goktepe \& Ozdemir cited in Mirko \& Mihajlović, 2014). The idea of using history of mathematics in mathematical education is not new. More than a century ago, Zeuthen (Furinghetti, Radford, 2002) wrote a book on the history of mathematics aimed for teachers. Zeuthen considered history of mathematics to be an integral part of general education of teachers. Almost at the same time, in 1894, Florian Cajori noticed in history of mathematics an inspirational source of information for teachers (Karaduman, 2010). In 1981, Freudenthal thought that introducing the history of mathematics into the education of mathematics teachers would provide a background to their mathematical knowledge (Lawrence, 2009).

The use of history of mathematical thought (HMT) in mathematics instruction has not received much attention, especially in Nigeria, where experience has shown that most teachers lack genuine interest in HMT and could not use it in mathematics instruction. The present paper aims to fill this gap by modeling the use of history of mathematical thought (HMT) in mathematics instruction. Mathematical modeling in this context can be viewed as the process of describing phenomena in terms of differential equations (Obasi, 2018). This paper is organized as follows. The model is formulated in Section 2 and solved in Section 2.1. Section 3 provides some concluding remarks based on the solution.

\section{RESEARCH METHODS}

The methodology of this paper is mathematical modeling approach. Mathematical modeling is the art of translating problems from an application area into tractable mathematical formulations whose theoretical and numerical analysis provides insight, answers, and guidance useful for the originating application (Obasi, 2018). It is the process of using various mathematical structures-graphs, equations, diagrams, scatterplots, tree diagrams, and so forth-to represent real world situations. The model provides an abstraction that reduces a problem to its essential characteristics. Mathematical modeling is indispensable in many applications. The rate at which HMT is used by teachers in mathematics instruction is assumed to be proportional to the number of teachers that do not use HMT. However, when forgetfulness is taken into consideration, the model is given as:

$\frac{d H}{d t}=k_{1}(N-H)-k_{2} H$

where

$k_{1}=$ factor that affects the rate of usage

$k_{2}=$ rate of non -usage or forgetfulness factor

$H(t)=$ number of teachers that use HMT in time, $t$

$N=$ total numbe of mathematics teachers

$N-H(t)=$ number of teachers that do not use HMT

\subsection{Solution of the Model Equation}

Using the method of integrating factor, the integrating factor is given by:

$\frac{d H}{d t}=k_{1}(N-H)-k_{2} H$

$\frac{d H}{d t}+k_{3} H=k_{1} N$,

where $k_{3}=k_{1}+k_{2}$

$e^{k_{3} t} \frac{d H}{d t}+k_{3} e^{k_{3} t} H=e^{k_{3} t} k_{1} N$

$\frac{d}{d t}\left(H e^{k_{3} t}\right)=k_{1} N e^{k_{3} t}$

$H e^{k_{3} t}=k_{1} N \int e^{k_{3} t} d t+k_{4}$

$H e^{k_{3} t}=\frac{k_{1}}{k_{2}} N e^{k_{3} t}+k_{4}$

$H(t)=\frac{k_{1}}{k_{2}} N+k_{4} e^{-k_{3} t}$

$H(t)=a N+b e^{-c t}$

Where $a=\frac{k_{1}}{k_{2}}=\frac{k_{1}}{k_{1}+k_{2}}>0, c=k_{3}=k_{1}+k_{2}>0$ and $b>0$

If $k_{2}=0, a=1$. This means that taking forgetfulness into consideration, it has reduced the proportion of the total number $N$ of teachers who use HMT in mathematics instruction. Now solving for the constants using the initial condition,

we have at $t=0, H(t) \rightarrow H_{0}$, then $H_{0}=a N+b \Rightarrow b=H_{0}-a N$

$\therefore H(t)=a N+\left(H_{0}-a N\right) e^{-c t}$

$H^{\prime}(t)=-\left(H_{0}-a N\right) c e^{-c t}$ and

$H^{\prime \prime}(t)=-\left(H_{0}-a N\right) c^{2} e^{-c t}$

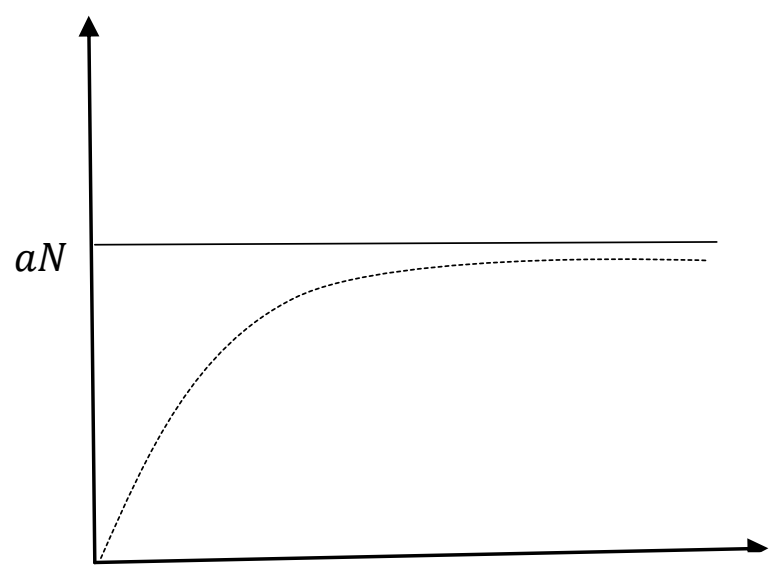

Figure 1: A graph $\mathrm{H}$ against time $(\mathrm{t})$

Since $H_{0}-a N<0$, it follows that $H^{\prime}(t)>0$ and $H^{\prime \prime}(t)<0 \forall t$, so the graph of $H(t)$ is always rising and is always concave down. Furthermore, the vertical ( $H$ axis) intercept is $H_{0}$ and $H=a N$ is a horizontal asymptote since :

$$
\lim _{t \rightarrow \infty} H(t)=\lim _{t \rightarrow \infty}\left[a N+\left(H_{0}-a N\right) e^{-c t}\right]=a N
$$




\section{CONCLUSION}

A graph with these features is sketched in Figure 1. The behaviour of the function as $t \rightarrow \infty$ reflects the fact that "in the long run", a fraction of teachers can use HMT in teaching mathematics due to the fact that they will not remember to use it, and additional recruitment of teachers will result in only marginal improvement in the usage of HMT. Moreover, using the history of mathematics has many benefits such as: increasing students' motivation, decreasing anxiety related to the subject, building positive attitude towards mathematics, better understanding and development of mathematical concepts, changing the students' perception about mathematics. It seems therefore that to learn mathematics, it is significant to follow the historical changes in mathematics. Besides knowing historical path of ideas, concepts and facts, which help us to form methodological path, we can create the basis for better understanding of contemporary concepts and views in mathematics, which will modernize methodical directions, which have been frequently outdated. In the teaching process, special attention should be given to developing positive attitudes of students towards mathematics (Dejić \& Mihajlović, 2014). One of the ways to achieve this is to show and convince the students that mathematical knowledge can make their life easier and improve it. But most importantly, a common sense tells us that mathematics teaching should be organized in the environment in which students will eagerly acquire new knowledge by their own intellectual efforts and abilities. One of the pedagogical tools for achieving these goals is history of mathematics thought.

\section{REFERENCES}

Dejić, M \& Mihajlović, A. (2014). History of mathematics and teaching mathematics. Teaching Innovations, 27 (3), 15-30.

Furinghetti, F. \& Radford, L. (2002). Historical conceptual developments and the teaching of mathematics: from phylogenesis and ontogenesis theory to classroom practice. In: D. L. English (Ed.). Handbook of Inter-national Research in Mathematics Education (631-654). Mahwah, NJ: Lawrence Erlbaum.

Karaduman, G. B. (2010). A sample study for classroom teachers addressing the importance of utilizing his-tory of math in math education. Procedia Social and Behavioral Sciences, Elsevier, 2, 2689-2693.

Lawrence, S. (2009). What works in the classroom project on the history of mathematics and the collaborative teaching practice. Paper presented at CERME 6, Lyon France. Retrieved on September 12th 2014, from http://ife.ens-lyon.fr/publications/edition-electronique /cerme6/wg15-08-lawrence.pdf

Obasi, C (2014). Correlation between students' performance in further mathematics and science subjects: A case of AMSS Owerri. Alvana Journal of Sciences, Vol. 8 (SE): 152-157.

Obasi, C (2018). A modified model of learning based on dynamic equilibrium theory of Hicklin. Alvana Journal of Sciences, Vol. 10 (1): 67-71.
Obasi, C (2018). Utilization of history of physics in motivating students to study physics using Verhulst logistic mathematical model. Alvana Journal of Sciences, Vol. 10 (1): 40-44. 